\title{
Evaluation of a housing programme
}

\author{
K. VASANTHA KUMAR \\ 1/30 Staff Quarters, Madurai Kamaraj University, Madurai 625 021, \\ India
}

The BMZ (German Federal Ministry of Co-operation) housing programme implemented through the German Leprosy Relief Association Rehabilitation Fund aims at providing houses for persons cured of leprosy and at improving their quality of life.

The housing programme was started in 1987 and has been implemented in 28 centres, benefiting 704 persons across India. In this programme, former leprosy patients were given interest-free loans of amounts ranging from Rs. 10,000 to 30,000 for the purpose of building a house of their own, to be paid back in instalments each month. The money is kept in the respective centres as a revolving fund from which loads for house construction are given to fresh applicants.

The programme was evaluated after 10 years to assess continuity and the benefits not only for leprosy cured persons but also for his/her whole family. The German Leprosy Relief Association Madras, the centre that receives the GLRA support to implement this programme, and the beneficiaries are the three main participants in the rehabilitation work. In this evaluation study, all three participants are included.

\section{Materials and methods}

For the purpose of evaluation, separate interview schedules were prepared for the three participants. The interview schedules for the Project Heads covered mostly the administration and monitoring of the programme and also their impressions of it. The interview schedule for the beneficiaries focused mainly on the benefits gained and their impressions.

The study covered 23 centres, which represents all the regions. All the 23 Project Heads and a sample of respondents were selected for interview. Table 1 gives the distribution by state of the centres selected, the sample from each centre and the total.

\section{Results}

The co-operation of the centres is greatly appreciated by the German Leprosy Relief Association Madras. The main problem with various centres is the delayed response for routine requests, which results in delayed start to the programme.

PROJECT CENTRES

The Project Centres selected for the study are involved in leprosy control work along with rehabilitation. The Project Heads expressed views that the leprosy cured persons should be 
Table 1. Centres and respondents by state

\begin{tabular}{llrr}
\hline State no. & \multicolumn{1}{c}{ State } & No. of centres & No. of respondents \\
\hline 1 & Tamil Nadu & 8 & 24 \\
2 & West Bengal & 2 & 6 \\
3 & Bihar & 2 & 6 \\
4 & Orissa & 1 & 3 \\
5 & Andhra Pradesh & 4 & 12 \\
6 & Kerala & 3 & 3 \\
7 & Rajasthan & 1 & 3 \\
8 & Maharashtra & 2 & 6 \\
& Total & 23 & 68 \\
\hline
\end{tabular}

supported through the housing programme, which helps them to live as normal persons in society; interest should not be charged for the loan distributed; and the loan amount should be raised when required.

The centres in urban areas like Calcutta and Madras find it difficult to identify the persons for whom the loan can be given, because finding a leprosy cured persons with necessary land documents is a difficult task. Some have managed this problem on their own initiative; for example, one centre has pooled all the money from the housing programme and added their own contribution to construct a decent house at the urban centre, while others have helped the beneficiaries to buy land by raising funds from other sources.

Centres have different opinions about collecting back the money from the beneficiaries. The slow progress in this aspect may be due to the lack of staff, or the attitude of the patients.

\section{BENEFICIARIES}

Of the 68 beneficiaries interviewed, 44 were males and the remaining 24 were females. Twenty-nine were from rural areas and 39 from urban areas. Fifty-one were Hindus, 11 Christians and six Muslims. Fifty-five were married, two were unmarried and 11 were widowed or separated. Forty-six claimed to be literate and 21 had some form of deformity.

The beneficiaries had different occupations, including unemployed (19), and business (17). They had acquired loans at different time periods, starting from 1987 to 1995 . Hence, the loan amount differed from one group of beneficiaries to another. When the programme was started, the loan amount was fixed as Rs. 10,000 each, which was gradually increased to Rs. 30,000 .

The centres followed different methods in distributing the loan amount. Some gave money directly to the beneficiary in two or three stages, as the construction work progressed, others paid the expenditure bills incurred by the beneficiary. Some centres also took charge of construction work, and while the burden on the beneficiary is reduced to a greater extent, the freedom to design and have a home to their own taste is lost.

The sufficiency of the loan amount is closely related to the size and type of the house one wants to have; in certain cases, the loan amount is not enough to complete a house. In the majority of cases, beneficiaries have invested their own funds to complete the construction. During the study, it was thought that beneficiaries would find it very difficult to manage the extra cost of the construction, but in fact no-one complained about this. In fact, they were all eager to raise more money and build a house. 
The beneficiaries also contributed their labour for building the house. The whole family participated in the construction, and the beneficiaries happily recollected how their relatives from far-off places came to help in the construction.

The housing scheme has improved the lifestyle and standard of living of former leprosy patients. Not all the beneficiaries were without a roof or living place before occupying their present house. To understand and appreciate the significance of the programme, one must know the brief family history of these beneficiaries.

A further 16 beneficiaries who had been living in rented huts built new homes of their own. Those who already had their own houses improved the condition of the house. Fiftythree beneficiaries now have tiled roofs. Electricity is available in 48 of the 68 houses visited. All the houses in urban areas have electricity. The houses in the rural areas of northern states in particular lack electricity. This is a feature common in every village, and is not specific to leprosy cured persons. A common complaint was the huge amount of money required to get a new electricity connection. Some beneficiaries asked for a further load to pay for this.

Only 26 houses had their own water source, that is, a well or tap water meant exclusively for their own use. In India, even in an urban area, people rely on public water systems. They do not plan for having a water supply in their own home, which explains why a number of beneficiaries do not opt for a water supply in their home. The beneficiaries do not like to have a toilet in their home, as a toilet is considered a luxury meant only for the rich. Constructing a toilet means additional expenses. It is interesting to note that the money given to a beneficiary to construct a toilet was instead used to build a kitchen.

Eleven beneficiaries have rented out a portion of their house to tenants. They seemed to have had this idea even before the construction of the house, as they built two separate units, one for themselves and the other for the tenant. Some beneficiaries have converted the front portion of their house as shops. Beneficiaries have therefore been able to turn the housing programme into an income-generating project.

Though the follow-up workers from many centres have reported poor repayment from the beneficiaries, in reality they have made significant progress in collection. From the study sample, 36 persons were found to be regular in their payments. The others paid as and when they were able.

\section{Conclusions}

Having a home has brought for the beneficiary a new social world. Some have married off their children. New babies have arrived. The social stigma, which is the greatest problem associated with this disease, has vanished in the beneficiaries' new-found life. 